\section{The Se.Ko.Ph. study: a European multicentre study on falls in elderly subjects living in residential homes}

\author{
Aladar Bruno Ianes, ${ }^{1}$ Giorgio Ricci, ${ }^{2}$ \\ for the Se.Ko.Ph. Study Group
}

${ }^{1}$ Segesta, Korian Group, Milan; ${ }^{2}$ RSA

Villa S. Clemente, Villasanta (MB), Italy

\section{Abstract}

The aim was to investigate risk factors for falls in elderly people living in residential nursing homes.

An observational, prospective, multicentre study was conducted between March 2010 and March 2011 investigating falls in elderly residents living in residential nursing homes (4 Italian, 4 French and 5 German nursing homes). A number of risk factors were assessed as well as details of the fall (dynamics, reasons, location and time of occurrence).

Differences were observed between the countries related to different nursing practices. Fallers comprised $36.5 \%$ of all residents and approximately $40 \%$ were injured as a consequence. Six logistic regression models were created to assess which fallrelated variables had the most impact, and showed subjects with faecal incontinence had a lower risk of falling, while subjects afflicted with dementia and visual impairment showed an increased risk of falling. Higher Tinetti scores were found to be related to an increased fall risk.

Falls in the elderly occur due to complex interactions between demographic, physical, behavioural and environmental risk factors. Differences between countries in fall rates were seen, probably due to different medical practices, use of aids and restraints, and characteristics of the populations (i.e. the Italian residents tended to be more cognitively impaired and more impaired in balance and gait compared to the French and German residents).

There was evidence that subjects with a better clinical status fall more frequently, whereas non-fallers had a worse clinical status and therefore tended to be more bedridden.

\section{Introduction}

Approximately $20 \%$ of the European population aged $\geq 65$ years with functional limitations receive long-term institutional care. ${ }^{1}$ This is projected to increase by approximately $120 \%$ in the next decade, with those requiring formal institutional care rising by approximately $130 \%{ }^{2}$

As people grow older they are increasingly at risk of falling and suffering consequent incurie. ${ }^{3,4}$ Approximately $30 \%$ of people $>65$ and $50 \%$ of those $>80$ fall each year. Furthermore, older adults who fall once are 2-3 times as likely to fall again within a year. ${ }^{5}$ Fall rates among institution residents are much higher than among community-dwellers, ${ }^{6}$ with the incidence of falls in institutional settings being 1.5 falls per bed per year. ${ }^{7}$ Indeed, nursing home residents aged $\geq 65$ years are approximately 3 times more likely to fall than their community-dwelling peers. ${ }^{8}$ Among people aged $\geq 85,20 \%$ of fall-related deaths occur in residential care settings. ${ }^{9}$

Falls often lead to reduced functioning and independence, which increases morbidity and mortality since around $20 \%$ of falls need medical attention, 5\% result in fractures, severe head injuries, joint distortions and dislocations, and $5-10 \%$ result in soft tissue contusions and lacerations. Fallinduced injuries are the fifth leading cause of death in elderly adults and are a common cause of longstanding pain and disability in this population. Falls account for $>80 \%$ of injury-related hospital admissions in people $>65$ years, ${ }^{10}$ and between $10-25 \%$ of nursing home falls result in fractures or hospital admissions. $^{8}$

The objective of this study was to evaluate risk factors of falls in elderly people living in nursing homes. Details of the fall including dynamics, reasons, location and time of the fall throughout the day were investigated and every nursing home resident was investigated considering a large number of variables regarding the health, cognitive and behavioral situation, independence in activities of daily living.

The duration of the study, the number of subjects studied, the large number of fall risk factors considered and having involved nursing home of three European countries with different medical and welfare approaches have given to this work added value compared to other research.

\section{Materials and Methods}

This observational, prospective, multicentre study involved elderly subjects living in 4 Italian (Segesta Group), 4 French (Korian Group) and 5 German (Phoenix Group) private nursing homes (the Se.Ko.Ph Study). The study was approved by the Italian Ethics Committee (registra-
Correspondence: Aladar Bruno Ianes, Segesta, Korian Group, viale Cassala 16, 20143 Milan, Italy. Tel.: +39.02.831271 Fax: +39.02 .83127190 .

E-mail: aladar.ianes@korian.it.

Key words: Accidental falls; elderly; health status; risk factors.

Acknowledgments: the authors would like to acknowledge all members of the Se.Ko.Ph. Study Group, and Debbie Jordan, a freelance medical writer for providing medical writing support.

Conflict of interest: the authors declare no potential conflict of interest.

\section{Se.Ko.Ph. Study Group}

Segesta Group - Italy

Barrionuevo Lucia Maria de Lourdes, Cosso

Paola, Pagliari Patrizia (RSA Villa San

Clemente, Villasanta [MB]), Barili Luca (RSA Saccardo, Milano), Bardoni Nadia (RSA Santa Marta, Milano), Rossetti Alberto, Luzzo Erika, Bruzzone Gianfranco (RSA Vado Sabatia).

Korian Group - France

Dohen René, Souverain Annette (Korian Pastoria, Troyes), Terrien Martine (Korian Artémis, Change), Solerti Agnès, Djebabra Kader (Korian Saison Dorée, Lyon), Lenart Anne, Amar Estelle, Amar Paul (Korian Les Sarments, Suresnes)

Phoenix Group - Germany

Worschech Iris, Tench Frieda

(Seniorenzentrum Am Bodenseering $\mathrm{GmbH}$, Bayreuth), Rehnen Michael, Kraus Johannes (Seniorenzentrum Fronmüllerstraße $\mathrm{GmbH}$,

Fürth), Farwick Petra, Hannig Marion (Seniorenresidenz Dettelbach GmbH Wohnstift, Dettelbach), Liebetrau Corinna, Helbig Heike (Haus Am Steinsgraben Senioren - und Pflegezentrum GmbH, Göttingen), Weikert Boris, Hopf Kerstin (Seniorenzentrum Im Brühl GmbH, Erfurt).

Received for publication: 16 March 2017

Revision received: 13 April 2017.

Accepted for publication: 20 April 2017.

This work is licensed under a Creative Commons Attribution-NonCommercial 4.0 International License (CC BY-NC 4.0).

(C) Copyright A.B. Ianes et al., 2017

Licensee PAGEPress, Italy

Geriatric Care 2017; 3:6712

doi:10.4081/gc.2017.6712

tion number 116/2010). All subjects present on the day of study commencement (T0: $15^{\text {th }}$ March 2010) who had been admitted to the nursing home for $\geq 24 \mathrm{~h}$ were included. Subjects were followed up after 12 months at study conclusion (T12: $14^{\text {th }}$ March 2011). 
Subject exclusion criteria included presence of coma, vegetative or minimally conscious status, locked-in syndrome, and length of stay $<12 \mathrm{~h}$.

The primary study outcome was the evaluation of risk factors for falls in elderly people living in nursing homes. A fall was defined as an unexpected event in which a person comes to rest on the ground, floor or other lower level. ${ }^{11}$ Secondary outcomes were to under stand more about the fall, i.e. dynamics, reasons why it occurred, where it happened, and time of fall.

All subjects were assessed using the multidimensional geriatric assessment at $\mathrm{T} 0$ and T12 irrespective of the presence of falls. This comprised demographics; date of nursing home admission; Folstein's mini mental state examination (MMSE) ${ }^{12}$ and hughes' clinical dementia rating (CDR). ${ }^{13}$ Autonomy in activities of daily living was assessed using the Tinetti balance and gait test $;^{14}$ and the nurses' observation scale for geriatric patients (NOSGER) ${ }^{15}$ was used to assess daily behaviour. Details were recorded of any diseases, conditions or drugs potentially related to falls. Use of aids (walking stick/crutch, wheelchair, walker) and use of restraints (bed rails, sleepsack, pelvic belt, abdominal belt, etc.) were noted. For each fall, a 13-item assessment was then completed, including time of fall, location, cause, awareness of falling, obstacles and environmental circumstances, and outcome.

All data collected at T0 and T12 were entered onto an Excel spreadsheet (version 1997-2003) and sent to the Central Co-ordinating Centre in Paris every 3 months. In cases of study discontinuation or death, subjects were still analysed, irrespective of the occurrence of falls.

\section{Statistical analysis}

Participants were divided in 3 groups: i) controls: no falls; ii) occasional fallers: one fall during study period; iii) multiple fallers: $\geq 2$ falls during the study period.

Statistical analysis was performed using SPSS version 13.0 (SPSS Inc, Chicago, Illinois, USA).

Bartlett's test for equal variances was performed to assess the differences between parametric data. ${ }^{16}$ Multiple comparisons between non-parametric data were analysed using Kruskal-Wallis Chi-squared test, ${ }^{17}$ while parametric data analysis of variance (ANOVA) for single and multiple factors was performed. ${ }^{18}$ Pearson's Chi-squared analysis for dichotomous variables tested the independence of 2 categorical variables. ${ }^{19}$ Cox proportional hazards regression for survival data was performed to evaluate the relationship between faller status and prognosis. ${ }^{20}$ Finally, 6 models were created to evaluate which group of variables were related to the risk of falls, and a final model was created using selected variables with $\mathrm{P}<0.05$ indicating statistical significance using logistic regression. ${ }^{21}$

\section{Results}

A total of 1017 subjects were enrolled (Germany 413, France 229, Italy 375). Most were females $(73.3 \%)$ and mean age at study inclusion was $84.5 \pm 8.9$ years.

Data concerning type of fall, reasons for Falling, and consequences of Falling are summarized in Table 1, while Table 2 summarizes the characteristics of the study population according to the frequency of falls.

Overall, $56.8 \%$ of subjects used technical aids: $25.6 \%$ used a wheelchair and $25.3 \%$ used a walker.

There were some differences in the types of aids used in the different countries, with the use of restraints being more frequent in Italy than in Germany and France (data not shown).

Of the 1,017 subjects, 371 fallers were recorded during the study $(36.5 \%)$. Of these, $168(45.3 \%)$ were occasional fallers and 203 $(54.7 \%)$ were multiple fallers. There was no significant difference between the countries in terms of fall prevalence.

Overall, 1091 falls were detected in $36.5 \%$ patients, with significant differences in the number of fallers between Germany and France $(35.8 \%$ vs $49.3 \%, \mathrm{P}<0.0001)$, and Italy and France $(29.3 \%$ vs $49.3 \%$, $\mathrm{P}<0.0006$ ), and in the number of falls occurring in Italy $(23.3 \%)$ compared to the other 2 countries (Germany: 37.2\%, France: $39.5 \%, \mathrm{P}<0.0001)$. Falls occurred mainly in the bedroom $(52.2 \%)$, communal spaces $(25.2 \%)$ and in the bathroom (14.2\%), with this trend seen across all 3 countries.

Falls were more frequent in the afternoon $(32.2 \%)$ and morning $(31.3 \%)$ compared to the evening (10.6\%) and night $(25.9 \%)$, however, there were differences between the countries. In France, falls occurred more frequently during the night $(32.1 \%)$ and morning (30.2\%), whereas in Italy, falls were more frequent in the morning $(35.1 \%)$, and in Germany, falls occurred particularly during the afternoon $(35.3 \%)$.

Falls were most commonly caused by stumbling or slipping $(45.7 \%)$, with a lower frequency in Germany $(23.8 \%)$ than in Italy $(52.4 \%)$ and France $(62.4 \%)$. Less frequent causes of falls were rash movement $(14.8 \%)$, with this being more common in Italy $(24.8 \%)$ than France $(8.0 \%)$ and Germany (15.8\%); and sudden loss of mus- cle tone $(14.0 \%)$, which was highest in the German subjects $(23.8 \%)$ (Table 1$)$.

Reasons for falling were categorised as a true accident (54.2\%), followed by interaction with the environment $(13.0 \%)$ and pathological causes $(8.0 \%)$. Drug side effects were only considered a key factor in $1.5 \%$ of all falls. However, some differences were noted between the 3 countries: interaction with environment was recorded in $23.8 \%$ of German fallers, but only in $6.9 \%$ of French and $6.7 \%$ of Italian fallers; moreover, idiopathic causes of falls was recorded in $17.2 \%$ of French and $13.7 \%$ of German subjects, but in only $4.3 \%$ of Italian fallers (Table 1).

Most falls did not result in any significant trauma $(62.1 \%)$, but in those who did suffer injury, painful soft tissue injury and haematoma was most common (17.9\%), followed by severe pain (7.4\%), and lacerated/contused wound (3.1\%). Fractures were detected in $3.0 \%$, most frequently being hip fracture (Table 1). 68.7\% of falls had possible psychological causes, the most common being overestimation of physical capacities $(52.8 \%)$, which was more frequent in Germany $(62.9 \%)$ and France $(51.1 \%)$, followed by confusion or stress $(12.9 \%)$, this being more common in Germany and Italy ( $15.8 \%$ and $14.2 \%$, respectively).

Significant differences were seen between non-fallers and occasional and multiple fallers for Tinetti scores $(\mathrm{P}<0.001)$, while significant differences in the NOSGER ADL scores were found between nonfallers and fallers $(\mathrm{P}<0.0088)$.

Finally, to evaluate which group of variables was associated with falls, 6 models were created and statistically analysed using logistic regression. The model 1 included as variables age, sex, and country, while the model 6 included all the variables studied in the other model with a statistical significance $(\mathrm{P}<0.05)$. The final model was generated considering the variables of the model 6 with statistical significance: faecal incontinence, visual deficit, dementia and Tinetti score.

Logistic regression showed that age and sex does not predict fall risk. Risk of falling is twice in France (odds ration $[\mathrm{OR}]=2$, $\mathrm{P}<0.0001)$ than in Italy and Germany. Subjects with faecal incontinence had a lower risk of falling, while subjects afflicted with dementia and visual impairment showed an increased risk of falling. All subjects showed a Tinetti score $<19$ points, indicating a high risk of falling. However, higher Tinetti scores were found to be related to an increased fall risk. It could be assumed that subjects with lowest Tinetti scores were not at risk of fall due to their bedridden state (Table 3 ). 


\section{Discussion}

Falls in the elderly occur due to complex interactions between demographic, physical, behavioural and environmental risk factors. This study investigated a number of risk factors in a large sample of elderly subjects (mean age $84.9 \pm 8.9$ years) living in nursing homes in 3 countries over a 12 -month period. Some differences were observed between the countries for age, chronic diseases, and pathologies and drug use, possibly due to differing medical practices. Assessment test scores showed Italians were more cognitively impaired than French and German subjects, having higher CDR scores.

Some differences were observed between the countries concerning number of fallers and number of falls. The distribution of falls over $24 \mathrm{~h}$ was similar between
Italy and Germany, but differed in France where there was a higher prevalence of falls during the night, possibly due to limited use of bedrails in those with poor gait and balance. The correlation between fall location and time of day was similar regardless of country and findings were consistent with previous data on Italian and German institutionalised populations in which falls were found to occur particularly in the afternoon and morning, and most commonly in the bedroom or other living spaces. ${ }^{22-24}$

The number of observed falls for the large number of subjects included in the study was low (1.072 falls per person/year), but there were differences between the countries (Italy 0.7, Germany 1.0, France 1.9), possibly reflecting lower Tinetti scale scores found in French subjects, as well as the low use of aids and restraints. The differences observed in the use of aids and restraints could be related to the different characteristics of the populations. Italian subjects were more cognitively impaired with respect to CDR, very impaired in balance and gait, and more impaired in terms of ADL. Moreover, Italian residents showed a higher prevalence of osteo-articular diseases, ischaemic heart disease, Parkinson's disease, psycho-behavioural disturbances and COPD, thus explaining the need for greater use of restraints, especially bedrails, pelvic belts and wheelchair straps. Approximately $40 \%$ of subjects were injured as a consequence of falling. A difference in fracture prevalence between Italy and the other 2 countries was found which may be due to the characteristics of residents who suffered an injurious fall: $60 \%$ were females, occasional fallers with low walking impairment who did not use restraints. Fallers comprised some $36.5 \%$ of the total study population (occasional fallers $16.5 \%$, multiple fallers $20.0 \%$ ), with this

Table 1. Type of fall, reasons for falling, and consequences of falling.

\begin{tabular}{|c|c|c|c|c|}
\hline & Germany & France & Italy & Total \\
\hline Type of fall (\%) & $\mathrm{N}=400$ & $\mathrm{~N}=425$ & $\mathrm{~N}=254$ & $\mathrm{~N}=1079$ \\
\hline Stumbling or slipping & 23.75 & 62.35 & 52.36 & 45.69 \\
\hline Rash movement & 15.75 & 8.00 & 24.80 & 14.83 \\
\hline Sudden loss of muscle tone - no loss of consciousness & 23.75 & 8.47 & 7.87 & 13.99 \\
\hline Collapse due to drowsiness or asthenia & 2.50 & 6.35 & 3.94 & 4.36 \\
\hline Dizzying sliding & 2.00 & 1.41 & 3.15 & 2.04 \\
\hline Loss of consciousness (syncope) & 0.25 & 1.18 & 0.79 & 0.74 \\
\hline Others & 36.50 & 17.41 & 7.09 & 22.06 \\
\hline Reason for fall (\%) & $\mathrm{N}=386$ & $\mathrm{~N}=417$ & $N=254$ & $N=1057$ \\
\hline True accident & 45.34 & 53.48 & 68.90 & 54.21 \\
\hline Drug assumption & 2.85 & 0.48 & 1.18 & 1.51 \\
\hline Pathological causes & 4.40 & 12.68 & 5.51 & 7.94 \\
\hline Idiopathic causes (not known) & 13.73 & 17.22 & 4.33 & 12.85 \\
\hline Interaction with environment & 23.83 & 6.94 & 6.69 & 13.04 \\
\hline Others & 15.54 & 10.05 & 12.20 & 12.57 \\
\hline Immediate consequences of fall (\%) & $\mathrm{N}=404$ & $\mathrm{~N}=410$ & $N=254$ & $\mathrm{~N}=1067$ \\
\hline None & 63.12 & 62.20 & 60.24 & 62.08 \\
\hline Painful injury of soft tissues - hematoma & 14.36 & 20.24 & 19.69 & 17.88 \\
\hline Severe pain & 10.89 & 6.83 & 2.76 & 7.40 \\
\hline Lacerated - contused wound $>2 \mathrm{~cm}^{2}$ & 1.98 & 4.39 & 2.76 & 3.09 \\
\hline Head injury & 0.25 & 0.98 & 5.12 & 1.69 \\
\hline Subdural hematoma & 0.00 & 0.00 & 0.39 & 0.09 \\
\hline Joint dislocation & 0.25 & 0.00 & 0.00 & 0.09 \\
\hline Fracture & 2.72 & 1.95 & 5.12 & 3.00 \\
\hline Reduced mobility secondary to the lesions related to the fall & 0.99 & 2.20 & 0.39 & 1.31 \\
\hline Reduced mobility secondary to fear or loss of confidence after the fall & 0.25 & 1.95 & 0.00 & 0.84 \\
\hline Hospitalization & 10.64 & 3.17 & 3.54 & 6.09 \\
\hline Death & 0.25 & 0.00 & 0.00 & 0.09 \\
\hline Others & 11.88 & 0.98 & 6.69 & 6.46 \\
\hline
\end{tabular}


finding being consistent across all 3 countries. Multiple fallers were affected by fewer cardiovascular diseases, and both multiple and occasional fallers were less impaired in gait and balance than non-fallers. These observations were also found in previous research on Italian nursing home residents in which the risk of falls was found to be higher in the population with highest level of autonomy in gait and balance as evidenced by the multidimensional performance oriented mobility assessment (POMA). ${ }^{25}$
There was evidence that subjects with a better clinical status fall more frequently, whereas nonfallers had a worse clinical status. Furthermore, non-fallers had a lower prevalence of faecal incontinence, fewer cardiovascular (only in multiple fallers) and osteo-articular diseases, and lower mortality in fallers and multiple fallers (although mortality seemed to be related more to age of admission and gender). The 6 logistic regression models used to assess which variables were related to falls showed an increased risk for those afflict- ed by dementia and visual impairment. A lower risk was observed in subjects with faecal incontinence, possibly linked to a worse clinical performance. Subjects with a higher Tinetti scores (i.e., better performance) had a higher risk of falling, while subjects with lowest Tinetti scores were not at risk of falling due to their bedridden state. These findings concur with other similar published studies. . $^{23,25-31}$

In conclusion, the rate of falls and related injuries in nursing homes should not be viewed as inevitable. Fall prevention

Table 2. Main characteristics of faller and relationship between faller status and standardized tests.

\begin{tabular}{|c|c|c|c|c|}
\hline & $\begin{array}{l}\text { Non fallers } \\
\mathrm{N}=646\end{array}$ & $\begin{array}{l}\text { Occasional fallers (1 fall) } \\
\qquad \mathrm{N}=168\end{array}$ & $\begin{array}{l}\text { Multiple fallers ( } \geq 2 \text { falls) } \\
\qquad N=203\end{array}$ & $\mathbf{P}$ \\
\hline \multicolumn{5}{|l|}{ Main characteristics } \\
\hline Age at inclusion (years) & $84.38 \pm 9.17$ & $84.83 \pm 8.03$ & $84.42 \pm 8.75$ & 0.8273 \\
\hline Age at admission (years) & $82.32 \pm 9.33$ & $82.78 \pm 8.21$ & $82.36 \pm 8.95$ & 0.8473 \\
\hline Length of stay (before inclusion) & $2.09 \pm 2.40$ & $2.04 \pm 2.48$ & $2.05 \pm 2.64$ & 0.9574 \\
\hline Number of chronic diseases & $5.52 \pm 2.61$ & $5.40 \pm 2.41$ & $5.11 \pm 2.43$ & 0.1297 \\
\hline Number of cardiovascular diseases & $1.11 \pm 0.90$ & $1.20 \pm 0.87$ & $0.95 \pm 0.82$ & $0.01^{*}$ \\
\hline Number of osteoarticular diseases & $0.66 \pm 0.84$ & $0.62 \pm 0.72$ & $0.60 \pm 0.71$ & 0.5376 \\
\hline Number of drugs & $6.77 \pm 3.11$ & $6.73 \pm 2.84$ & $7.16 \pm 3.11$ & 0.2564 \\
\hline \multicolumn{5}{|l|}{ Standardized tests (mean \pm SD) } \\
\hline CDR score & $1.82 \pm 1.07$ & $1.66 \pm 1.10$ & $1.86 \pm 1.01$ & 0.1443 \\
\hline MMSE score & $17.00 \pm 8.21$ & $17.02 \pm 8.05$ & $15.46 \pm 7.92$ & 0.0805 \\
\hline $\begin{array}{l}\text { Tinetti total score } \\
\text { Balance score } \\
\text { Gait score }\end{array}$ & $\begin{array}{c}10.67 \pm 9.71 \\
5.72 \pm 5.31 \\
4.98 \pm 4.71\end{array}$ & $\begin{array}{l}13.88 \pm 8.50 \\
7.32 \pm 4.91 \\
6.56 \pm 3.99\end{array}$ & $\begin{array}{l}13.79 \pm 8.02 \\
7.36 \pm 4.61 \\
6.43 \pm 3.91\end{array}$ & $\begin{array}{l}0.001^{* *} \\
0.001^{* *} \\
0.001^{* *}\end{array}$ \\
\hline $\begin{array}{l}\text { NOSGER total score } \\
\text { ADL score } \\
\text { Memory score } \\
\text { IADL score } \\
\text { Mood score } \\
\text { Social behavioral score } \\
\text { Behavioral disorders score }\end{array}$ & $\begin{array}{c}85.01 \pm 25.13 \\
15.51 \pm 6.80 \\
14.79 \pm 5.92 \\
18.74 \pm 6.17 \\
11.68 \pm 3.89 \\
16.55 \pm 5.92 \\
7.72 \pm 2.91\end{array}$ & $\begin{array}{c}80.54 \pm 24.00 \\
13.97 \pm 6.41 \\
13.92 \pm 5.71 \\
17.64 \pm 6.08 \\
11.43 \pm 3.78 \\
15.65 \pm 5.72 \\
7.94 \pm 3.14\end{array}$ & $\begin{array}{c}84.05 \pm 24.36 \\
14.41 \pm 6.17 \\
14.54 \pm 5.59 \\
18.60 \pm 5.91 \\
11.46 \pm 4.24 \\
16.27 \pm 5.45 \\
8.77 \pm 4.15\end{array}$ & $\begin{array}{c}0.1158 \\
0.008^{* * *} \\
0.2147 \\
0.1123 \\
0.6524 \\
0.1962 \\
0.0526\end{array}$ \\
\hline
\end{tabular}

ANOVA (if $\mathrm{P}>0.05$ at Barlett's test for equal variances) or Kruskal-Wallis (if $\mathrm{P}<0.05$ at Barlett's test for equal variances). *Significant difference between fallers and multiple fallers; ${ }^{* *}$ significant difference between non fallers and fallers and between non fallers and multiple fallers; ${ }^{* * *}$ significant difference between non fallers and fallers.

Table 3. Logistic regression (final model).

\begin{tabular}{|c|c|c|c|c|c|}
\hline & OR & SE & $\mathbf{Z}$ & $P>|z|$ & $95 \%$ CI \\
\hline Age & 1.002 & 0.008 & 0.20 & 0.842 & {$[0.986-1.017]$} \\
\hline Sex & 1.116 & 0.178 & 0.69 & 0.491 & {$[0.817-1.524]$} \\
\hline \multicolumn{6}{|l|}{ Country (ref. Germany) } \\
\hline France & 2.008 & 0.367 & 3.82 & 0.000 & {$[1.404-2.873]$} \\
\hline Italy & 0.986 & 0.188 & -0.07 & 0.944 & {$[0.679-1.434]$} \\
\hline \multicolumn{6}{|l|}{ Selected variables } \\
\hline Faecal incontinence visual & 0.596 & 0.116 & -2.65 & 0.008 & {$[0.407-0.874]$} \\
\hline Deficit & 1.470 & 0.216 & 2.62 & 0.009 & [1.102-1.961] \\
\hline Dementia & 1.500 & 0.229 & 2.65 & 0.008 & {$[1.111-2.024]$} \\
\hline Tinetti score & 1.039 & 0.008 & 4.76 & 0.000 & [1.022-1.055] \\
\hline Constant & 0.216 & 0.147 & -2.24 & 0.025 & {$[0.056-0.824]$} \\
\hline
\end{tabular}

Variables: age, sex, country + selected variables with $\mathrm{P}<0.05$. 
requires effective intervention to address multiple factors including medical treatment, rehabilitation and environmental issues. Furthermore, multi-dimensional clinical assessment can be used to identify those elderly persons who are at greatest risk of falling.

Analyzing the results of the study have highlighted some limitations.

First: in the study it has emerged some fragility due to the difference between the multidimensional evaluation and the diagnosis of dementia. For example no significant differences were seen in the MMSE scores between countries, but the Italian population had higher CDR score and a higher number of subjects diagnosed as demented. This bias in the diagnosis and in the assessment could be attributed to a different organization of the nursing home in the three countries: in Italy the multidimensional evaluation is performed by a trained physician, often by a geriatrician, while in the other countries the evaluation is entrusted to a nurse.

This problem must be corrected in the event of future studies to try to standardize the evaluation methods because the role that cognitive impairment has on the prevalence of falls.

Second: the need to synthesize certain items in setting the type of fall or the reason of fall could be the cause of inaccuracy in the data recording. For example, stumbling is different from slipping, so it has been impossibile to defyne the real event in this case. Moreover, the term idiopathic causes seems too used in France and Germany and we cannot be sure that the fall so classified was really unexplainable. The same problem has arisen with the definition of interaction with the environment, because there was too much difference in the use of this definition between Germany and the other two countries. The problem of definitions must therefore be carefully defined in future studies

Finally, the role of drugs such as fall risk factors has not been sufficiently investigated and the sensitivity to recognize the therapy as a possible cause of the fall is not yet refined enough. This issue is crucial for the proper management of the person with dementia in nursing home and will have to be considered in future studies.

\section{Conclusions}

In conclusion, we think that, despite these limitations, the study represents, both for the sample size, length of follow up, and the large number of subjects examined, an important basis for other studies to be undertaken on a larger sample and a longer period possibly widening number of countries involved on a larger sample and a longer period possibly widening number of countries involved

\section{References}

1. Giannakouris K. Ageing characterizes the demographic perspectives of the European societies. Eurostat Stat Focus 2008;72:1-11.

2. Pickard L, Comas-Herrera A, CostaFont J, et al. Modeling an entitlement to long-term care services for older people in Europe: projections for long-term care expenditure to 2050. J Eur Soc Pol 2007;17:33-48.

3. Campbell AJ, Spears GF, Borrie MJ. Examination by logistic regression modelling of the variables which increase the relative risk of elderly women falling compared to elderly men. J Clin Epidemiol 1990;43:1415-20.

4. Robbins AS, Rubenstein LZ, Josephson $\mathrm{KR}$, et al. Predictors of falls among elderly people. Results of two populationbased studies. Arch Int Med 1989;149: 1628-33.

5. O'Loughlin JL, Robitaille Y, Boivin JF, Suissa S. Incidence of and risk factors for falls and injurious falls among the community-dwelling elderly. Am J Epidemiol 1993;137:342-54.

6. Todd C, Skelton D. What are the main risk factors for falls among older people and what are the most effective interventions to prevent these falls? Copenhagen: WHO Regional Office for Europe - Health Evidence Network report; 2004. Available from: http:// www.euro.who.int/document/E82552.p df Accessed: 7 April 2014.

7. Rubenstein LZ, Josephson KR, Robbins AS. Falls in the nursing home. Ann Int Med 1994;121:442-51.

8. Vu MQ, Weintraub N, Rubenstein LZ. Falls in the nursing home: are they preventable? J Am Med Dir Assoc 2005;6: S82-87.

9. Friedman SM, Williamson JD, Lee BH, et al. Increased fall rates in nursing home residents after relocation to a new facility. J Am Geriatr Soc 1995;43: 1237-42.

10. Kannus P, Parkkari J, Niemi S, Palvanen M. Fall-induced deaths among elderly people. Am J Public Health 2005;95:422-4.

11. Kerse N, Peri K, Robinson T, et al. Does a functional activity program improve function, quality of life and falls for residents in long term care? Cluster randomized controlled trial. BMJ 2008; 337:a1445.

12. Folstein MF, Folstein SE, McHugh PR. ""Mini-mental state". A practical method for grading the cognitive state of patients for the clinician". J Psychiatr Res 1975;12:189-989.

13. Hughes CP, Berg L, Danziger WL, et al. A new clinical scale for the staging of dementia. Br J Psychiatr 1982;140: 566-72.

14. Tinetti ME. Performance-oriented assessment of mobility problems in elderly patients. J Am Geriatr Soc 1986; 34:119-26.

15. Wahle M, Häller S, Spiegel R. Validation of the NOSGER (nurses' observation scale for geriatric patients): reliability and validity of a caregiver rating instrument. Intern Psychogeriatr 1996;8:525-47.

16. Bartlett MS. Properties of sufficiency and statistical test. Proc R Stat Soc Series A 1937;160:268-82.

17. Kruskal WH, Wallis WA. Use of ranks in one-criterion variance analysis. J Am Stat Assoc 1952;47:583-621.

18. Scheffé $H$. The analysis of variance, New York, NY: Wiley; 1952.

19. Pearson K. On the criterion that a given system of deviations from the probable in the case of a correlated system of variables is such that it can be reasonably supposed to have arisen from random sampling. Philos Magazine 1990; 50:157-75.

20. Cox DR. Regression models and life tables (with discussion). J Royal Stat Soc Series B 1972;34:187-220.

21. Hilbe JM. Logistic regression models. Boca Raton, FL: Chapman \& Hall, CRC Press; 2009.

22. Ricci G, Bodini S, Cosso P, et al. Falls in the elderly: Who, When, Where and Why falls in nursing home. 19th IAGG World Congress of Gerontology and Geriatrics, Paris 5-9 July 2009. J Nutr Health Aging 2009;13:S264.

23. Ricci G, Cosso P, Franchi L, et al. Studio osservazionale sulla dinamica, gli esiti e le caratteristiche di autonomia dei soggetti caduti in RSA. Geriatr Med 2008;3:134-9.

24. Rapp K, Becker C, Cameron L, et al. Epidemiology of falls in residential aged care: analysis of more than 70000 falls from residents of Bavarian nursing homes. J Am Med Dir Assoc 2012;13: 187.e1-6.

25. Ricci G, Barrionuevo ML, Bodini S, et al. Balance, gait and falls in an elderly institutionalized population: one year 
monitoring by performance oriented mobility assessment (POMA). Giorn Gerontol 2012;60:88-98.

26. Vaapio S, Salminen M, Vahlberg T, et al. Effects of risk-based multifactorial fall prevention on healthy related quality of life among community-dwelling aged: a randomized controlled trial. Health Qual Life Outcomes 2007;5:20-7.

27. Lord SL. Visual risk factors for falls in older people. Age Ageing 2006;35: ii42-5.

28. Lin $\mathrm{CH}$, Liao $\mathrm{KC}, \mathrm{Pu} \mathrm{SL}$, et al. Associated factors for falls among the community-dwelling older people assessed by annual geriatric health examination. PLoS One 2011;6:e10976.

29. Davis JW, Ross PD, Nevitt MC, Wasnick RD. Risk factors for falls and for serious injuries on falling among older Japanese women in Hawaii. J Am Geriatr Soc 1999;47:792-79.

30. Bergland A, Jarnio GB, Laake K. Predictors of falls in the elderly by location. Aging Clin Exp Res 2003;15:43-50.

31. Tinetti ME, Speechey M, Ginter SF. Risk factors for falls among elderly persons livingin the community. N Engl J Med 1988;319:1701-7. 